\title{
TECNOLOGIAS EDUCATIVAS COMO ESTRATÉGIA DE CONSTRUÇÃO DO CONHECIMENTO COM BASE NO MÉTODO CONSTRUTIVISTA
}

\author{
Mateus Andrade Ferreira, Universidade Federal de Campina Grande (UFCG-CFP), \\ mateus0297@gmail.com \\ Paulo José de Andrade, Universidade Federal de Campina Grande (UFCG-CCTA), \\ paulojosedeandrade@yahoo.com.br \\ Marcelo Costa Fernandes, Universidade Federal de Campina Grande (UFCG-CFP), \\ celo_cf@hotmail.com
}

\section{RESUMO}

O desenvolvimento de metodologias para potencializar a construção de conhecimentos no cotidiano escolar tem sido um dos temas mais abordados pelos estudiosos dessa área de conhecimento. No presente trabalho objetivamos refletir a teoria construtivista de Vygotsky realizando um estudo teórico e reflexivo acerca desta teoria na construção de novos conhecimentos, usando como instrumento mediador jogos educativos através dos quais se estimula a participação dos discentes proporcionando a aquisição dos saberes no processo ensino - aprendizagem.

PALAVRAS-CHAVE: tecnologias educativas; jogos educativos; construtivismo.

\section{EDUCATIONAL TECHNOLOGIES AS A CONSTRUCTION STRATEGY OF KNOWLEDGE BASED ON THE CONSTRUCTION METHOD}

\begin{abstract}
The development of methodologies to potentialize the construction of knowledge in school life has been one of the most approached topics by scholars in this area of knowledge. In the present work we aim to reflect Vygotsky 's constructivist theory by carrying out a theoretical and reflexive study about this theory in the construction of new knowledge, using educational games as mediator instrument whereby the participation of the students is stimulated, providing the acquisition of knowledge in the teaching - learning process.
\end{abstract}

KEYWORDS: educational technologies, educational games, constructivism 


\section{TECNOLOGÍAS EDUCATIVAS COMO ESTRATEGIA DE CONSTRUCCIÓN DEL CONOCIMIENTO CON BASE EN EL MÉTODO CONSTRUTIVISTA}

RESUMEN

El desarrollo de metodologías para potenciar la construcción de conocimientos en el cotidiano escolar ha sido uno de los temas más abordados por los estudiosos de esa área de conocimiento. En el presente trabajo pretendemos reflejar la teoría constructivista de Vygotsky realizando un estudio teórico y reflexivo acerca de esta teoría en la construcción de nuevos conocimientos, utilizando como instrumento mediador juegos educativos a través de los cuales se estimula la participación de los alumnos proporcionando la adquisición de los saberes en el proceso enseñanza - aprendizaje.

PALABRAS CLAVE: tecnologías educativas; Juegos educativos; Constructivismo.

\section{INTRODUÇÃO}

Lev Semenovitch Vygotsky, cientista bielorrusso, foi um dos principais autores que trataram do construtivismo em seus escritos. Essa filosofia traz para o contexto da educação um conceito de conhecimento, no qual este deve ser construído de maneira social, a partir das interações e mediações características desse processo.

Para Vygotsky, o ser humano está em constante interação com o meio sociocultural em que reside. Essa relação ocorre de maneira dialética entre os indivíduos promovendo aprendizado e transformações em si próprios e no ambiente. Portanto o conhecimento não advém de nenhum tipo de hereditariedade, mas apenas dessa construção promovida pelas relações sociais entre os indivíduos, levando em consideração os estímulos do ambiente (HEIMANN et al., 2013).

O processo de construção do conhecimento, para o construtivismo, deve levar em consideração o contexto do indivíduo, que é composto pela interação entre suas disposições internas (conhecimentos prévios) e os novos estímulos recebidos no seu meio. Essa construção passa por um processo de interiorização dos estímulos que serão submetidos a 
uma reflexão crítica e comparados ao saber prévio para que haja formação de novas aptidões (THOFEHRN; LEOPARDI, 2006).

O educador deve assumir uma posição de problematizador das questões a serem trabalhadas e de mediador do processo de aprendizado garantindo ao discente um ambiente que o instigue a reflexão e análise dos conhecimentos já adquiridos a partir de novas experiências. A mediação favorece o empoderamento do aluno, tornando-o capaz de ser sujeito ativo na construção do processo de ensino e aprendizagem (HEIMANN et al., 2013).

Para que haja efetivação do aprendizado, Vygotsky criou o conceito de Zona de desenvolvimento proximal (ZDP), onde esta é a distância daquele conhecimento que o indivíduo já domina (nível de desenvolvimento real) para aquele que ele pode alcançar através da utilização de ferramentas mediadoras (nível de desenvolvimento potencial) que o auxiliam a ampliar sua capacidade cognitiva (THOFEHRN; LEOPARDI, 2006).

Assim, a ZDP envolve a constante criação de relações sociais para resolução de problemas, onde na grande maioria dos casos existe um processo de evolução das funções que saem do nível potencial e se tornam integrantes do desenvolvimento real. Esse processo ocorre a partir das interações sociais e da mediação.

O modelo tradicional de aulas expositivas tem relegado muitas vezes ao aluno a função de receptor passivo dos conteúdos, onde este deve apenas reter e repetir os assuntos ministrados sem que seja necessário qualquer tipo de análise crítica (GURGEL; FERNANDES, 2015). Esse modelo vai contra a teoria de Vygotsky que prima por um sujeito ativo na construção do conhecimento e um ambiente desafiador para que esse processo possa acontecer.

Considerando esta perspectiva educacional o uso das tecnologias educativas, com destaque para os jogos educacionais, pode servir como ferramentas educativas criando um ambiente propício à troca de saberes e o desenvolvimento do processo de ensino e aprendizagem, defendido pela ótica construtivista.

Assim sendo, as tecnologias aplicadas a educação surgem como uma maneira inovadora de repensar o modelo de ensino, trazendo novas abordagens aos conteúdos que serão ministrados. Para que haja o bom uso dessas tecnologias o conteúdo (conhecimento) a ser veiculado e a forma a ser utilizada (instrumentos) devem estar de acordo com a realidade apresentada e os objetivos à serem alcançados (OLIVEIRA, 2015). 
A utilização dos jogos educacionais fornece os instrumentos e as experiências necessárias para o desenvolvimento cognitivo dos sujeitos. Para que isso seja possível é necessária a presença da ludicidade na criação e implementação desses jogos (SANTAELLA, 2012).

A ludicidade se refere a elementos dos jogos que prenderão a atenção e proporcionarão um momento de divertimento para os envolvidos, é através dela que os alunos serão impelidos a participarem da atividade pedagógica explorando ao máximo as capacidades das ferramentas de ensino. Essa característica deve ser alcançada por situações que desafiem, provoquem curiosidade e entretenham os participantes.

\section{OBJETIVOS}

Refletir a teoria construtivista de Vygotsky para compreensão das tecnologias educativas como estratégia de construção de novos conhecimentos.

\section{METODOLOGIA}

Trata-se de um estudo teórico e reflexivo, que utilizou o modelo construtivista de Vygotsky, para compreensão das tecnologias educativas como estratégia de construção de novos conhecimentos.

Estudo realizado por pesquisadores integrantes do Grupo de Pesquisa do $\mathrm{CNPq}$ Laboratório de Tecnologias de Informação e Comunicação em Saúde (LATICS - UFCG), do qual o autor principal deste estudo participa.

\section{RESULTADOS E DISCUSSÕES}

O ser humano, enquanto ser racional, interioriza elementos culturais da sociedade em que vive. A interação presente nesse processo, garante incremento nas percepções do indivíduo a respeito do seu meio. Nesse processo mediado por outros sujeitos mais experientes, o indivíduo dá origem a novos conhecimentos ao mesmo tempo que constrói suas 
ações e interfere em sua realidade. Situações de aprendizagem acompanhadas pela mediação impulsionam o desenvolvimento do indivíduo (SOUZA; ROSSO, 2011)

Os jogos educativos, a partir da visão construtivista, servem como ferramenta para o surgimento de interações do indivíduo com o meio em que está inserido, facilitando as relações de construção do conhecimento de acordo com contexto vivido (RIBEIRO et al., 2015). Sendo assim, o uso dessas tecnologias possibilita aos docentes a inserção dos alunos em um ambiente de produção de saberes onde serão empoderados a se tornarem promotores do processo de ensino-aprendizagem.

As tecnologias educativas podem enriquecer as aulas convencionais e realizar ações que outras metodologias não alcançam (OLIVEIRA, 2015). Elas podem tornar o processo de ensino aprendizagem mais rico, interessante e instigador agindo de maneira complementar as metodologias tradicionais e dependendo do contexto até substituí-las. O uso destes instrumentos colabora para que haja um salto qualitativo no desenvolvimento cognitivo dos alunos.

Segundo Santaella (2012), os jogos educativos devem ser capazes de cativar o aluno e incentivá-lo a trabalhar os conteúdos contidos na tecnologia de maneira ativa e integral, o que resultará no processo de aprendizado. Assim, as reflexões críticas e as relações sociais preconizadas pela teoria construtivista surgem no próprio ato de jogar com o avanço dos objetivos e a interação com os outros participantes sob a mediação do docente. Esses objetivos devem ser bem definidos e serem capazes de contemplar todos os conteúdos pretendidos.

O educador age como mediador na construção do conhecimento do estudante, ele deve criar situações que desenvolvam o empoderamento do aluno e sua independência. Dentre essas práticas, o uso de jogos educacionais age como facilitador da relação dialética entre aluno, professor e conhecimento. Essas atividades favorecem o desafio ao discente para instigá-lo a buscar o saber (GURGEL; FERNANDES, 2015).

A figura do professor não deve ser depreciada pelo argumento de que seus aprendizes, através do construtivismo, assumem papel ativo no processo de ensino aprendizagem. Pelo contrário, o docente se torna ainda mais indispensável na construção do conhecimento visto a necessidade da figura mediadora, provida de mais experiência, para efetivação das relações sociais produtivas. 
A aquisição dos novos saberes através do firmamento dos conhecimentos potenciais aos conhecimentos reais pode, então, ocorrer a partir do ambiente criado pelos jogos educativos. A competitividade, o trabalho em equipe, o papel ativo e a troca de saberes proporcionada pelo contexto do jogo estabelecem as relações sociais em torno daquele tema que uma vez mediado pelo docente promove a vivência necessária para construção dos conhecimentos.

\section{CONSIDERAÇÕES}

A abordagem construtivista do modelo de ensino defende o empoderamento do discente na construção do conhecimento. A utilização dessa teoria no ensino proporciona a criação de ambientes que favorecem a independência e o pensamento crítico dos alunos que aprendem mais conteúdos, pois se interessam mais, e com mais qualidade, visto que a reflexão crítica permeia todo o processo.

Os jogos educacionais surgem como alternativa para complementar e em alguns casos substituir o modelo tradicional de ensino. Eles figuram como possíveis ferramentas estruturantes do processo de ensino aprendizagem proposto por Vygotsky uma vez que criam o ambiente e as situações favoráveis a construção do conhecimento. Por isso, devem ser inseridos e cada vez mais utilizados nas instituições de ensino não só com finalidade recreativa, mas como instrumentos de ensino.

Por fim, os educadores necessitam possuir conhecimentos a respeito da importância e do funcionamento dessas ferramentas de ensino. Para que isso seja possível são necessários incentivos para o a implantação e criação de novos jogos, que devem garantir o aprendizado dos alunos sem abrir mão da ludicidade que proporciona os desafios e a motivação para aproveitamento da tecnologia.

\section{REFERÊNCIAS}

GURGEL, P. C.; FERNANDES, M. C. Educational games in nursing teaching of public health: experience report. Rev enferm UFPE on line., Recife, v. 9, n. 9, p. 9320-9323, setembro 2015. Disponível em: 
<https://periodicos.ufpe.br/revistas/revistaenfermagem/article/download/10733/11835>. Acesso em: 14 agosto 2017.

HEIMANN, C. et al. A construção do conhecimento da enfermagem baseada no método construtivista. Rev. esc. enferm. USP, São Paulo, v. 47, n. 4, p. 997-1000, agosto 2013.

OLIVEIRA, J. B. A. Repensando a educação brasileira. São Paulo: Atlas, 2015.

RIBEIRO, R. J. et al. Theories of Learning in Educational Games: a Brazilian Overview. Revista Novas Tecnologias na Educação, Porto Alegre, v. 13, n. 1, p. 1-10, julho 2015. Disponível em: < http://www.seer.ufrgs.br/renote/article/viewFile/57589/34562 >. Acesso em: 14 de agosto de 2017.

SANTAELLA, L. O papel do lúdico na aprendizagem. Revista Teias, Rio de Janeiro, v.13, n. 30, p. 185-195, setembro/dezembro 2012.

SOUZA, A. P.; ROSSO, A. J. Mediação e Zona de Desenvolvimento Proximal (ZDP): entre pensamentos e práticas docentes. In: CONGRESSO NACIONAL DE EDUCAÇÃO: EDUCERE, 10., 2011, Curitiba. Anais... Curitiba: CHAMPAGNAT, 2011. v. 1, p. 5894 5906.

THOFEHRN, M. B.; LEOPARDI, M. T. Construtivismo sócio-histórico de Vygostky e a enfermagem. Rev. bras. enferm., Brasília, v. 59, n. 5, p. 694-698, outubro 2006. 